\title{
Simulating Movement Devices Used in Hospital Evacuation
}

\author{
Aoife L. E. Hunt (D) and Steven M. V. Gwynne, Movement Strategies, London, \\ $U K$ \\ Edwin R. Galea, Peter J. Lawrence* and Ian R. Frost, Fire Safety Engineering \\ Group, University of Greenwich, London, $U K$
}

Received: 31 August 2017/Accepted: 16 January 2020

\begin{abstract}
In hospitals, the evacuation of those with severe movement impairments can be highly problematic for the patients, for the staff and for other evacuees. It is critical to understand the performance of horizontal and vertical evacuation procedures, including the means by which people with reduced mobility can be assisted during stair descent. Microsimulation modelling provides a useful tool to assess evacuation strategies, given the challenges of preparing and transporting patients in need of on-going care and the unfeasibility of real evacuation drills. However, current simulation models typically focus on the movement of individual agents, not the staff-patient interactions and sizable equipment required to carry out assisted evacuation. To address this, the buildingEXODUS evacuation model has been enhanced to represent moving objects in addition to moving individual agents. This paper describes the modelling theory behind this development, where dedicated data has been applied to enable the explicit specification of evacuation devices, operated by agents (for instance, representing the vertical travel speeds achieved-with averages ranging between $0.6 \mathrm{~m} / \mathrm{s}$ and $0.84 \mathrm{~m} / \mathrm{s}$ - when employing different movement devices). Algorithms are presented that calculate the movement of devices along corridors, through doorways and in stairway descent, including a method of geometric decomposition of the available hospital evacuation routes. This new functionality addresses the key evacuation components of repeated patient collection and has numerous applications, both in simulating hospital evacuation and in representing evacuation of other premises that include people with reduced mobility. Examination of the performance of this functionality found it predicated performance within $6 \%$ of expectation. Once further testing is completed, the resultant tool can be used to significantly enhance planning and diagnostic capabilities related to the evacuation of hospital and other healthcare facilities.
\end{abstract}

Keywords: Evacuation simulation, Hospitals, Healthcare evacuation, People with reduced mobility, Assist devices, Fire evacuation

* Correspondence should be addressed to: Peter J. Lawrence, E-mail: P.J.Lawrence@greenwich. ac.uk 


\section{Introduction}

Planning for the evacuation of hospitals and healthcare facilities from a fire incident presents a number of unique challenges. It is common for hospitals to have large and complex building structures, while wards have different uses and different staffing structures. There is high staff turnover; therefore, frequent training is required [1]. However, staff training can be problematic as live hands-on drills are often impractical [2]. Areas in healthcare facilities have highly variable occupancy levels and, importantly, patients may require assistance and continuing care dependent on their clinical needs. It can be expected that there will be large numbers of vulnerable occupants and people with reduced mobility (PRM) - a far greater proportion than would be expected in other buildings.

In comparison to other building types, patients in hospitals are more likely to await personal staff instruction on hearing an alarm given their vulnerability and lack of familiarity with the procedure in place; therefore, staff are vital to the evacuation strategy employed [3]. To evacuate PRM staff might have to make many trips, assisting individual patients in turn. This is physically demanding and requires triage procedures to organise, enhance and monitor the process. Evacuating patients is particularly challenging when many require assistance: when the staff to patient ratio is low (e.g. on a night shift), when the structural configuration is complex, and when vertical movement is required. In addition, the size of movement assist devices (alone and in conjunction with the number and identity of handlers) and hospital beds can create moving obstacles while transferring patients, potentially delaying the evacuation of others.

While fire and rescue services are crucial in any hospital fire event, the emphasis for evacuation planning is on in-house procedures. For example, to meet legal requirements in the UK, the emergency response must be designed under the assumption that there will be no evacuation assistance from the fire and rescue services [4]. Typical procedures avoid full building evacuations as this can place highly dependent patients (e.g. those with severe medical conditions) at risk and compromise the functionality of the hospital. The most common strategy is progressive horizontal evacuation, which is conducted in stages to limit the number of people impacted and reduce the distress that might be caused to vulnerable patients. Premises are divided into compartments and sub-compartments, constructed to provide required levels of fire safety. In the event of a fire, occupants are progressively moved into adjacent compartments away from the fire. The concept of horizontal evacuation reduces the number of patients to be moved, as long as fire compartmentation is effective. This approach is based on a three-stage procedure [5]. Those in the fire sub-compartment are initially moved to an adjoining compartment or sub-compartment, using beds or wheelchairs for PRM. If a second stage is deemed to be necessary, patients are then moved from the entire fire compartment to an adjoining compartment. Additional horizontal evacuation may be required before the third stage: vertical evacuation to a lower floor, or to the outside. In adopting this approach, those most exposed to the fire incident are given priority, while attempting to minimize the distress caused to the patients involved. 
When assessing risk, it is typically expected that horizontal evacuation will be sufficient and that full hospital evacuation is unlikely to be required. However, incidents have revealed that it can be also necessary to fully evacuate an entire hospital [6-8] and while elevators may be used, guidance has highlighted that it is essential that provision be made for vertical (stairway) evacuation of patients without the use of lifts [5]. This requires the use of movement assist devices to transport PRM down stairs; for example, hospital rescue sheets, carry chairs, evacuation chair, stretcher, etc. The perception that horizontal evacuation is likely to be sufficient has led to a lack of focus in risk assessments on the vertical component [9]. This leaves gaps in planning for large-scale assisted evacuation and in the provision of training and equipment such as movement assist devices for evacuation down stairs.

To address the complexities of planning for evacuation, many countries are now incorporating performance-based alternatives to increase design flexibility over previous prescriptive building codes, enabling safety performance levels to be established $[1,10,11]$. This represents an evidence-based approach of evaluating evacuation performance, with fire modelling used to estimate the Available Safe Egress Time (ASET) and evacuation modelling used to estimate the Required Safe Egress Time (RSET). This approach allows comparison of the performance of different designs in certain scenarios. The goal is to ensure that ASET > RSET including a safety factor to incorporate a margin of error [12]. Performance-based design requires fire safety engineering: a method of design that assesses performance to demonstrate that it meets regulatory objectives, without necessarily adhering to detailed prescriptive codes.

Simulation can support this fire safety engineering approach by quantifying performance using stochastic (dynamic) modelling. Commercially-available software has been developed to simulate the fire development [13] and/or the evacuation process [14], and are employed internationally as part of performance-based design efforts. Agent-based models (e.g. STEPS [15] and MassMotion [16]), simulate the circulation and evacuation of individuals to gauge a building's expected performance during egress. However, the application of these and other models to the hospital environment has proved challenging [17-22]. Many models represent ambulatory differences between people and have incorporated mobility distributions; however, the models that represent PRM have done so by simply modifying their walking speeds or the size of the ambulant individuals (as opposed to devices), not by explicitly representing the devices required to transport them. This only represents one facet of the dynamics of assisted evacuation (i.e. the reduced travel speed) rather than the many others that might exist for the PRM and to those around them (e.g. inability to use certain routes, occupying more space, etc.). For instance, not modelling the movement device might misrepresent the impact on the space occupied, the navigational impact on other pedestrians, and the impact on route availability. Some models represent wheelchair users $[15,16$, 23-25], but are not able to reflect the shape and increased footprint of these devices, particularly in vertical movement and the impact they might have on navigation, manoeuvrability, speed, and on the movement of the adjacent population. Understanding this impact has been shown to be key in assessing the effectiveness 
of a procedure (or a device) in moving vulnerable populations to safety [26]. The Pathfinder model has recently been developed to now include functionality to physically represent the device and its associated impact on performance. The Pathfinder model is a continuous model, where location and movement are coordinate-based rather than the nodal system described here. As such, the implementation of the functionality described herein is different-requiring different geometrical considerations. The work described here is significantly different from that applied in the Pathfinder model and (as far as the authors are aware) represents the first peer-reviewed description of an attempt to embed such functionality within a simulation tool. ${ }^{1}$

Several movement assist devices are available to transport PRM during an evacuation. However, there are only a few data-sets that can be used to quantify the performance of these devices. In conjunction with the mathematical challenges involved in simulating the effect of movement devices, the absence of supporting data also represents an important hurdle to their representation.

The previous discussion highlights several points. The combination of structural, procedural and occupant issues make planning safety strategies for healthcare facilities particularly challenging. The array of interacting factors means that analytically (or intuitively) identifying the effectiveness of procedural strategies becomes highly problematic. Recent international legislation requires equivalent safety practices for all occupants [27, 28]. When coupled with expected demographic changes, this means that a growing population of movement-impaired people need to be supported in evacuation strategies. Historical safety procedures may not be sufficient given the evidence provided by recent incidents. Recent regulatory practices have spawned a generation of engineering tools designed to quantify evacuation performance. These are typically generic in nature. Engineering/ simulation tools that can quantify performance are particularly valuable in a healthcare environment. However, such tools require dedicated functionality to represent the peculiarities of the hospital environment (e.g. PRM movement) and require data on which to build these functionalities. There is a paucity of such developments and such data.

The work presented here uses experimental data to inform the development of dedicated functionality within an existing evacuation simulation tool to quantify PRM evacuation performance. This represents a significant advance on many fronts: in the understanding of PRM movement in evacuation devices, the quantification of this movement, and the representation of this movement within a simulated environment. This advance allows fire protection engineers and healthcare providers to assess the effectiveness of their building designs and procedural strategies to ensure a hospital population reaches a place of safety in the time available.

\footnotetext{
${ }^{1}$ During the review of this article the Pathfinder model was updated to include the impact of movement devices based on the same data as the work described in this article. A description of the Pathfinder functionality can be found here (https://www.thunderheadeng.com/wp-content/uploads/dlm_uploads/20 11/07/users_guide-7.pdf accessed 12/2019).
} 


\section{Model Requirements}

Table 1 provides an overview of the simulation functionality that is required within modelling software to represent the key components of hospital evacuation. As identified by a systematic review of the literature [22], the crucial development needed in simulating hospital evacuation is the explicit representation of the devices used to evacuate PRM. It requires a geometrical representation that reflects its movement and the space it occupies, as well as the human factors associated with its use. The theoretical model developed to address this also advances the ability to represent other human-manoeuvred objects, such as prams, trolleys and luggage in evacuation scenarios. While this work focuses on the development of sim-

\section{Table 1 \\ Required Model Functionality for Hospital Evacuations According to Hospital Evacuation Considerations}

Hospital evacuation consideration

Required model functionality

\section{Population \\ Hospitals contain a diverse range of people with varying attributes, conditions and capabilities}

\section{Procedural}

Hospitals employ complex procedures that are conditional on the extent of the danger present, as well as the needs of the occupants. The use of emergency equipment is critical to the success of an evacuation

\section{Behavioural}

As part of an evacuation, staff engage in several activities including patient preparation and repeated collection and triage. Patient-staff interaction and group behaviours are exhibited

\section{Environmental}

Hospitals have a complex layout with many beds, furniture and equipment. An incident may develop over time prompting full evacuation. There may be locked doors, and emergency lifts

\section{Population}

The ability to represent a varied population The ability to represent individual attributes such as age, height, weight, walking speeds, delays and stair speeds

Procedural

The ability to construct scenarios to represent evacuation procedures, including the time taken to prepare patients

The ability to represent repeated patient collection The ability to closely scrutinise scenarios and the individual actions of agents in order to analyse and compare the effectiveness of different procedures

The ability to model the emergency equipment currently in use during hospital/healthcare evacuations

\section{Behavioural}

The ability to represent individual behaviours

The ability to represent group behaviours

The ability to assign tasks to staff members, including the time taken to prepare patients for evacuation

The ability to represent fatigue as staff repeatedly evacuate patients

\section{Environmental}

The ability to specify the layout and furniture in the hospital setting

The ability to represent evolving conditions that might affect route availability and route conditions (e.g. the spread of fire effluent)

The inclusion of locked and unlocked doors The ability to represent the use of evacuation lifts 
ulation tools for movement devices in hospitals, its widely applicable functionality is developed in general and versatile terms in order to be useful in other applications. As such, this paper describes functionality that can be generalised as "objects", and functionality that is specific to movement devices as "devices" throughout this paper.

\subsection{Data}

There is a clear need to understand the performance of assisted evacuation procedures and efforts have been made in recent years to collect data in experimental settings. Of topical focus is data describing the evacuation of people with disabilities, with equality legislation highlighting the need to make reasonable adjustments for the evacuation of PRM [27], and considering the ageing population [29, 30].

PRM typically walk at significantly lower speeds than ambulant people when unassisted, and may require aids (e.g. walking sticks and frames) to evacuate [26]. Some PRM may be able to travel unassisted for a short distance before requiring assistance, for example elderly people, pregnant women, and those on crutches. Others will require full assistance for the whole evacuation procedure. While some PRM may be able to travel along corridors using walking aids, these may not be effective on stairwells. Table 2 categorises some of the means by which PRM may be assisted. This list represents those categories which have published data on their performance in vertical/horizontal evacuation. The average (mean) speeds of these data sets are presented in Table 3, alphabetically per author, and in the categories outlined in Table 2.

These data should be compared against the data that represent the movement of those evacuees without a movement impairment (e.g. those in the SFPE handbook [31]); i.e. none of the existing data reflects the specific context for a hospital or healthcare scenario. From the data-sets available, the reduction in movement can reach over $50 \%$ indicating that simply assuming the movement capabilities of an unimpaired evacuee may significantly overestimate their performance and potentially reduce the safety margin of the design (e.g. [26, 32]).

The data described in Table 3 represents an important repository. However, it is insufficient in two important ways. Firstly, the data does not capture the use of movement devices in physical environments comparable to those used in hospital/ healthcare facilities. Secondly, the data presented is not detailed enough to be employed within a simulation tool to represent the passage of such devices. For instance, a device might traverse a chain of horizontal and vertical terrain separated by doors that need to be operated. The manner in which doors are operated and the interaction between the device design and the environment will be sensitive to the number and type of operators; i.e. factors that might influence performance. Given this, new trials were required to produce data that complements the data already presented.

The data used to develop the theoretical model presented in this work is taken from the University of Ghent hospital evacuation experiment in 2008, designed by Adams and Galea [33]. Detailed analysis was undertaken to quantify the perfor- 


\section{Table 2}

Data Categories Used to Describe Performance of Evacuating PRM

\begin{tabular}{|c|c|}
\hline Label & Description \\
\hline A & PRM was assisted \\
\hline UA & PRM was unassisted \\
\hline NA & No aid was used \\
\hline VI & PRM was visually impaired \\
\hline CR1 & PRM used one crutch \\
\hline CR2 & PRM used two crutches \\
\hline WC & PRM used a manual wheelchair \\
\hline EWC & PRM used an electric wheelchair \\
\hline WF & PRM used a walking frame \\
\hline WS & PRM used a walking stick \\
\hline $\mathrm{F}$ & Fire fighters assisted PRM in evacuation \\
\hline $\mathrm{CWC}$ & A carried wheelchair was used to transport PRM down stairs \\
\hline $\mathrm{EC}$ & An evacuation chair ( 2 wheeled) was used to transport PRM down stairs \\
\hline ST & A stretcher was used to transport PRM down stairs \\
\hline $\mathrm{CC} 3 / 4$ & The PRM was carried down the stairs in a Carry Chair by three or four handlers \\
\hline RS & A drag sheet was used to transport the PRM down stairs \\
\hline EC4 & An evacuation chair ( 4 wheeled) was used to transport PRM down stairs \\
\hline ECL & A long track evacuation chair was used to transport PRM down stairs \\
\hline ECR & A rear-facing evacuation chair was used to transport PRM down stairs \\
\hline $\mathrm{ECN}$ & A narrow evacuation chair ( 2 wheeled) was used to transport PRM down stairs \\
\hline $\mathrm{MC}$ & The PRM was manually carried down the stairs by two handlers \\
\hline $\mathrm{CC} 2$ & The PRM was carried down the stairs in a Carry Chair by two handlers \\
\hline FS & The PRM was carried down the stairs in a Fabric Seat by two handlers \\
\hline $\mathrm{ECC}$ & The PRM was carried down the stairs in an Extended Handle Carry Chair by two handlers \\
\hline
\end{tabular}

mance of trained hospital staff in evacuating non-ambulant patients. As depicted in Table 4, four commonly used movement devices were tested: stretcher, carry chair, evacuation chair, and rescue sheet. Hospital staff from the manual handling team of the University of Ghent Hospital served as device operators during the trials; all were expert in the manual handling of patients and in the use of each of the devices. The data from these trials therefore quantify the performance capabilities of the devices in expert hands, providing an indication of the best performance that can be expected using each of the devices. The staff were allocated to four handling teams: two teams consisted of four male handlers and two teams of four female handlers. These 32 trials were specifically conducted both to quantify the performance of the devices over an 11-storey vertical evacuation and to develop this theoretical model, providing empirical support for the simulation process. Trials were conducted for each device with four handling teams (Male 1, Male 2, Female 1 and Female 2). Before each trial, the handling team was positioned behind a starting line on the $11^{\text {th }}$ floor of the hospital building. An audible signal marked the start of the trial, at which point the handling team collected the device, entered the room with the PRM, prepared the device and transferred the PRM to the device, exited the room, moved down a corridor through several 


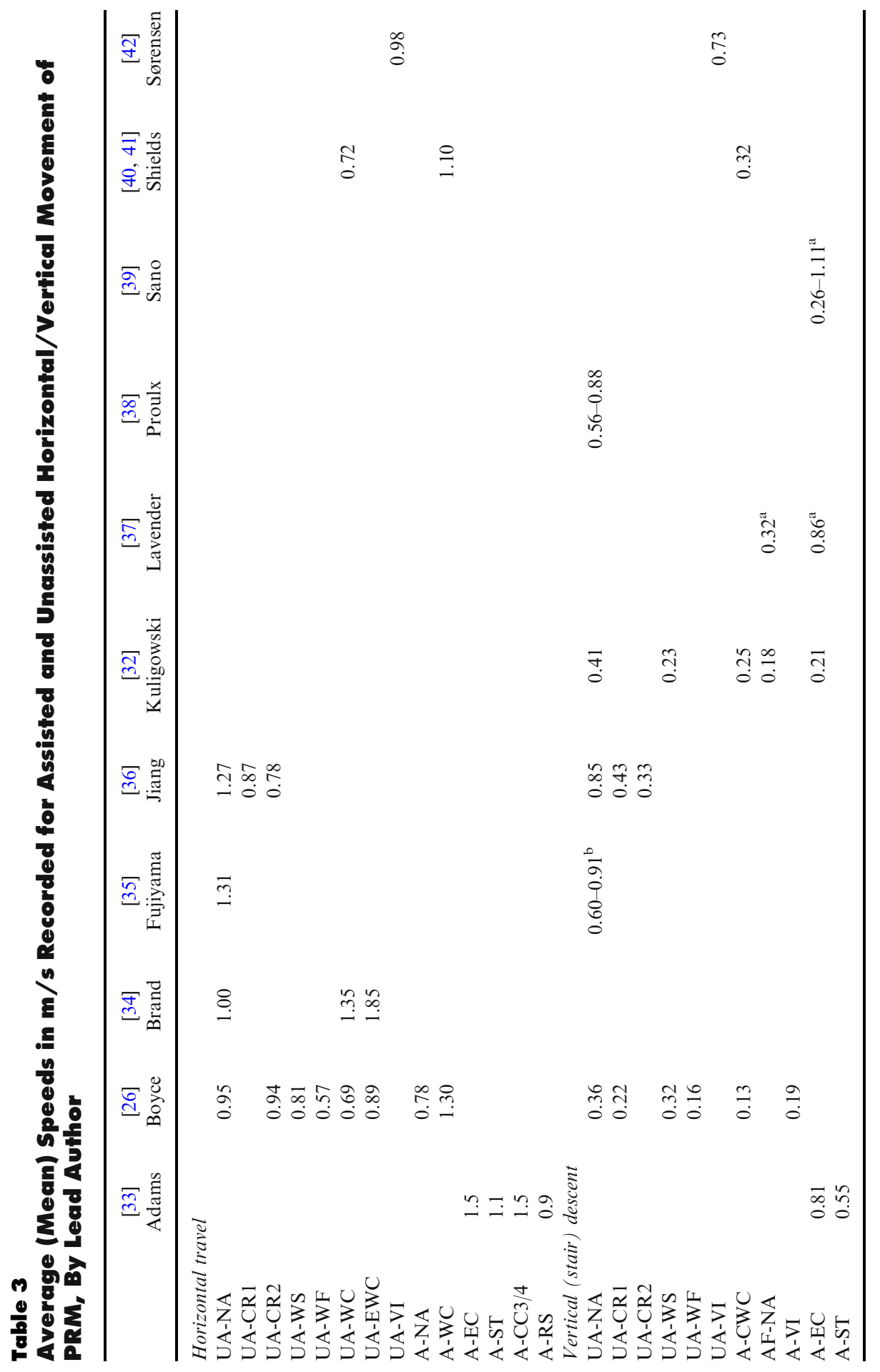




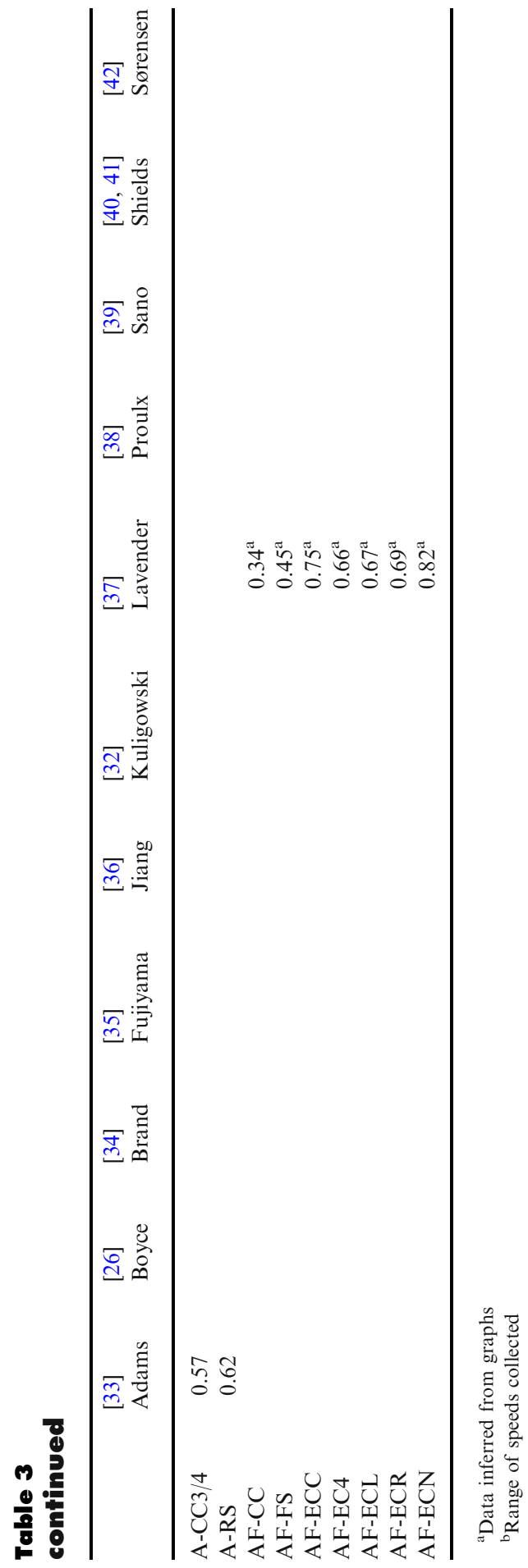




\section{Table 4}

\section{The Attributes (Design Material and Dimensions) of Four Commonly Used Movements Assist Devices}

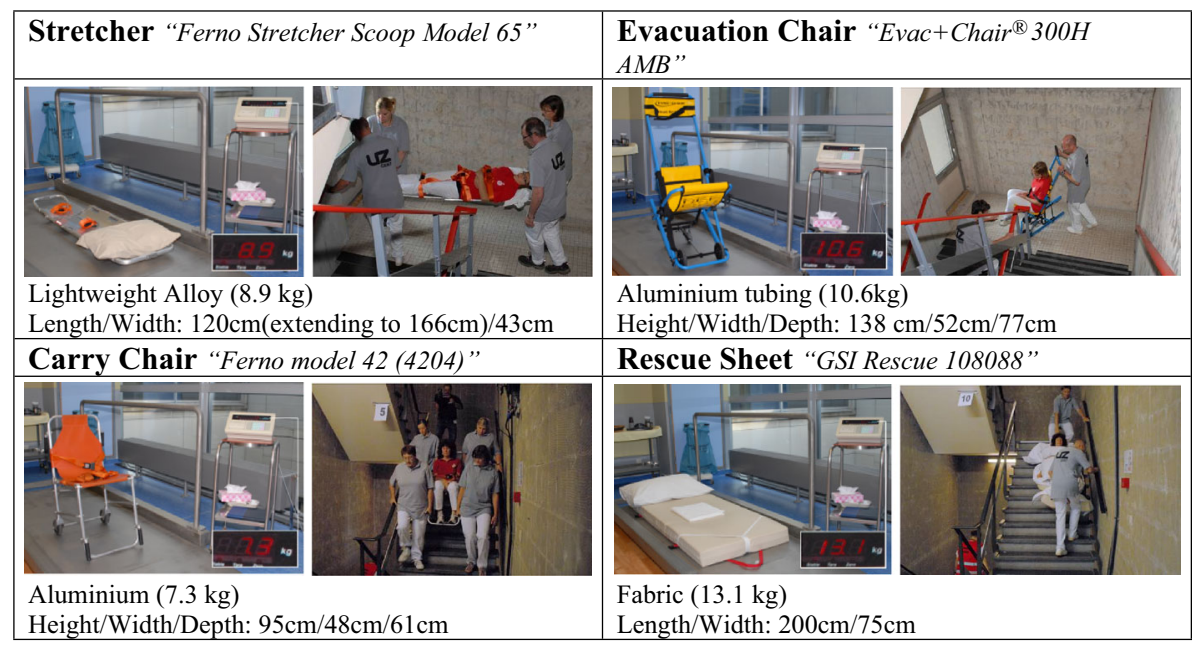

doors, turned several corners, entered the stairwell, descended to the ground floor and then exited the building. The trials consisted of three main phases: a preparation phase, a corridor phase and a stairwell phase. A total of 13 video cameras were positioned in the stairwell; one camera placed in the same position on each floor, one on the ground floor and an additional camera on the landing between floor 4 and floor 3. A member of our team operated a roaming camera during each trial that followed (at a safe distance) the handling team and recording every phase of the experiment.

The most comprehensive data analysis from this experiment, conducted by Hunt et al. [43], informs the following theoretical model development by quantifying the key processes of assisted evacuation: the time taken to prepare a patient, the speeds on the horizontal and vertical, the time taken to go around corners and through doors, the time taken to rest in the stairwell over an 11-storey journey, the potential for others to overtake, and the difference between the performance of male and female operators.

\section{Theoretical Model Development}

This section presents a synoptic outline of the Object Model (OM) developed to represent human-operated objects within evacuation software. The model developments presented here were implemented within buildingEXODUS V6.0 (bEX) [44], and forms part of a $\mathrm{PhD}$ project undertaken by the lead author while at the Fire Safety Engineering Group of the University of Greenwich [22]. bEX allows 
agents to move around a nodal grid (that represents occupiable space), with the nature and connectivity of the nodes affecting their movement and performance

To fully integrate within the software, it is important that the objects specified here can interact with the other sub-models within bEX. Therefore, in addition to the OM, the full range of existing capability is required, including the group and leadership behaviours, the wayfinding and signage features, the interaction and conflict resolution with other occupants, and the potential for pairing with the fire simulation software SMARTFIRE [45], in order to ensure that the additional developments represented are able to interact as expected with the existing model functionality. The methodologies presented here are designed to preserve these established interactions by integrating with this existing bEX functionality where possible.

\subsection{Object Model Parameters}

As discussed in the previous section, the raw data collected by Adams and Galea [33] and the detailed performance analysis by Hunt et al. [43] is used as a basis for the model development. Table 5 outlines the parameters required to fully specify the OM as categorised by delays $(d)$, speeds $(s)$, number $(n)$, and measurements $(m)$. Each device represented requires the definition of all of these parameters, for which there are separate distributions for all-male and all-female device operating teams.

\subsection{Object Model Overview}

The OM works in pre-simulation and simulation modes. In the first instance, building structures (e.g. egress pathways) are assessed before simulation commences to pre-determine viable routes. There is then a system under which an object is specified, including: its dimensions, shape analysis, travel direction, handler positioning, and performance data. During simulation, horizontal and vertical algorithms then govern movement, including travel through doorways, and the periodic stopping of on stairwells, as documented in the Ghent trials.

Figure 1 provides an overview of the OM, during pre-simulation and simulation stages, including the associated movement algorithms, agent itineraries, and model parameters. In the following sections, each sub-model is then described in turn.

\subsection{Route Assessment}

This sub-model constitutes a pre-simulation analysis of the hospital geometry, employed in advance of the computational simulation. After it has assessed a building structure for object manoeuvrability, it prescribes the routes available to objects, enabling them to navigate during evacuation simulations on the existing fine node mesh as an individual agent does; albeit occupying numerous nodes at once. It is therefore designed to align with, and to directly interact with, the established pedestrian and evacuation dynamics in the fine node model bEX.

In bEX, structural designs such as CAD drawings, are discretized into nodes that represent the position of individuals within the geometry. For the OM route 


\section{Table 5}

Object Model Parameters That Affect Performance

\begin{tabular}{|c|c|c|}
\hline & Parameter (units) & Description \\
\hline$d_{p}$ & Preparation time (s) & Range of average preparation time \\
\hline$d_{d 1}$ & Door transition time $1(\mathrm{~s})$ & $\begin{array}{l}\text { Average time recorded to open left, then right door lea- } \\
\text { ves }^{\mathrm{a}}\end{array}$ \\
\hline$d_{d 2}$ & Door transition time $2(\mathrm{~s})$ & $\begin{array}{l}\text { Average time recorded to open right, then left door lea- } \\
\text { ves }^{\mathrm{a}}\end{array}$ \\
\hline$d_{s}$ & Stoppage duration (s) & Average stopping duration on stairs \\
\hline$d_{r}$ & Device retrieval time $(\mathrm{s})$ & Nominated delay for readying device for evacuation \\
\hline$s_{h}$ & Horizontal speed (m/s) & Distribution of average horizontal speeds \\
\hline$s_{v}$ & Interpolated vertical speed $(\mathrm{m} / \mathrm{s})$ & Average interpolated speed when stoppages are removed \\
\hline$s_{c}$ & $\begin{array}{l}\text { "Carry empty device upstairs" speed } \\
(\mathrm{m} / \mathrm{s})\end{array}$ & $\begin{array}{l}\text { Nominated speed for ascending stairs while carrying } \\
\text { device }\end{array}$ \\
\hline$n_{s}$ & Stopping frequency (no.) & Average number of stops. per 10 flights of stairs \\
\hline$n_{p}$ & $\begin{array}{l}\text { Number of agents for preparation } \\
\text { (no.) }\end{array}$ & The number of people in "essential" preparation role. \\
\hline$n_{h}$ & $\begin{array}{l}\text { Number of agents for horizontal travel } \\
\text { (no.) }\end{array}$ & $\begin{array}{l}\text { The number of people in "essential" horizontal travel } \\
\text { role }\end{array}$ \\
\hline $\boldsymbol{n}_{v}$ & $\begin{array}{l}\text { Number of agents for vertical travel } \\
\text { (no.) }\end{array}$ & The number of people in "essential" vertical travel role \\
\hline$n_{l}$ & Stair lanes occupied (no.) & The number of lanes occupied on the stairs \\
\hline$m_{s}$ & Distance between stoppages $(\mathrm{m})$ & Average distance between device stoppages on stairs \\
\hline$m_{l}$ & Device length $(\mathrm{m})$ & $\begin{array}{l}\text { The length of a device: parallel to direction of move- } \\
\text { ment }{ }^{b}\end{array}$ \\
\hline $\boldsymbol{m}_{w}$ & Device width $(\mathrm{m})$ & $\begin{array}{l}\text { The width of the device: perpendicular to direction of } \\
\text { movement }\end{array}$ \\
\hline
\end{tabular}

${ }^{\text {a }}$ The direction of operation differs according to door type with the associated delays being applied

${ }^{\mathrm{b}}$ The length and width of the device is important in establishing viable egress routes

assessment, a Generalized Voronoi Diagram (GVD) is constructed as per the following definition [46]: let a set of geometric objects be denoted $s_{1}, s_{2}, \ldots s_{n}$. For each site $s_{i}$, define a distance function $d_{i}(x)=\operatorname{dist}\left(s_{i}, x\right)$. The Voronoi region of $s_{i}$ is the set $V_{i}=\left\{x \mid d_{i}(x) \leq d_{j} \forall j \neq i\right\}$. The collection of regions $V_{1}, V_{2}, \ldots V_{n}$ is called the GVD.

Considering the map of a hospital as a shape within which routes will be determined, the points on the Medial Axis (MA) of a map are a subset of those in the GVD [47]: they are the set of Voronoi points that are interior to the shape. To numerically approximate the MA, a Proximity Field Generator (PFG) specifically developed within the SMARTFIRE [45] tool is used in the OM. This PFG evaluates a $2 \mathrm{D}$ geometry by imposing onto it a regular mesh of $m * m$ squares. Sequentially, the loci of points equidistant from the contours of the shape in the map approximate an MA, as depicted by the additional black lines in Fig. 2.

The MA can now be interrogated, when considered as the locus of centres of maximal circles [48] and along with its Radius Function (RF), to describe the space within a shape. The MA and the RF together constitute the Medial Axis Transform (MAT) [49]. Figure 2 depicts the MA, with the heat map representing 


\section{Pre-Simulation Stage: Route Assessment}

The building geometry is assessed to determine whether the device of length $\boldsymbol{m}_{\boldsymbol{l}}$ metres and width $\boldsymbol{m}_{\boldsymbol{w}}$ metres will fit along evacuation routes.

bEX Agent Movement
Algorithms
Agent Itineraries:
- Delay
- Target Node
- Pick up object
- Coordinated
Delay
The device is retrieved (with a delay of $\boldsymbol{d}_{\boldsymbol{r}}$ seconds) and carried to PRM (at speed
$\left.\boldsymbol{s}_{\boldsymbol{c}} \mathrm{m} / \mathrm{s}\right)$. A group is formed until $\boldsymbol{n}_{\boldsymbol{p}}$ agents are at the device, and preparation
commences (with a delay of $\boldsymbol{d}_{\boldsymbol{p}}$ seconds).

Horizontal Movement
Algorithm
Agent Itineraries:
- Target Node
- Form Group
If $\boldsymbol{n}_{\boldsymbol{p}} \neq \boldsymbol{n}_{\boldsymbol{h}}$, members leave/join the group until $\boldsymbol{n}_{\boldsymbol{h}}$ agents are at the device. The device
is transported horizontally (at speed $\left.\boldsymbol{s}_{\boldsymbol{h}} \mathrm{m} / \mathrm{s}\right)$. If a door $($ of type 1 or 2$)$ is encountered, the
speed of the device is reduced (to speed $\boldsymbol{m}_{\boldsymbol{l}} / \boldsymbol{d}_{\boldsymbol{d} \mathbf{2}}$ or $\left.\boldsymbol{m}_{\boldsymbol{l}} / \boldsymbol{d}_{\boldsymbol{d} \mathbf{1}} \mathrm{m} / \mathrm{s}\right)$ until the whole device
has traversed the doorway.

has traversed the doorway.

\section{Vertical Movement} Algorithm

Agent Itineraries:

- Target Node

- Form Group

- Drop off object

- Coordinated Delay
Simulation Stage 3: Vertical Movement
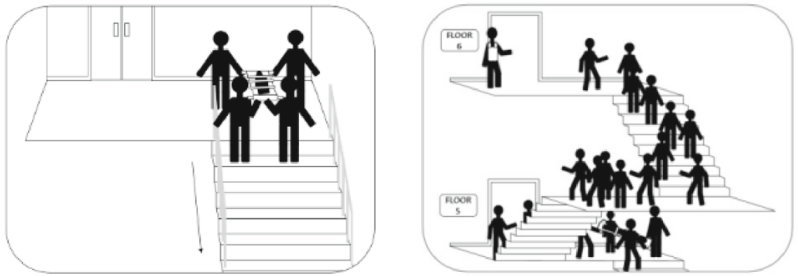

If $\boldsymbol{n}_{\boldsymbol{h}} \neq \boldsymbol{n}_{\boldsymbol{v}}$, members leave/join the group until $\boldsymbol{n}_{\boldsymbol{v}}$ agents are at the device. The device is transported vertically (at speed $\boldsymbol{s}_{\boldsymbol{v}} \mathrm{m} / \mathrm{s}$ ) and occupies $\boldsymbol{n}_{\boldsymbol{l}}$ lanes. During its descent, the device will stop periodically $\left(\boldsymbol{n}_{\boldsymbol{s}}\right.$ times per ten flights of stairs, with a delay of $\boldsymbol{d}_{\boldsymbol{s}}$ seconds). These stops will be at a maximum of $\boldsymbol{m}_{\boldsymbol{s}}$ metres apart, but may also occur more frequently, based on the population density preceding the device.

\section{Figure 1. Object model overview according to simulation stage.}


distances to the nearest boundaries, and two possible routes of the MAT as approximated with a mesh. The routes are not intended to prescribe the path that an object would take, but instead assess the geometric conditions along the route prescribed.

In these examples, the mesh is constructed of $0.1 \mathrm{~m}$ squares; therefore the theoretical error is: $\varepsilon \leq 0.071 \mathrm{~m}$. However, the method used for proximity calculations means that the approximate distance will always be less than or equal to the true distance; i.e. points will always be considered too close to a boundary instead of too far away. To improve this approximation, the mesh size could be reduced or adaptive meshing included for curves in the geometry [50].

Once defined, the paths themselves are scrutinised to assess whether any $90^{\circ}$ corners (with entrance and exit widths of $a$ and $b$ ), are present on the route. These are also noted on Fig. 2, where the labels represent the automatic corner detection. Whether devices (of width $w$ and length $l$ ), can fit around these corners, can also be established [51]:

$$
\max L=\sqrt{\left(\left(1+\frac{1}{x^{2}}\right)\left(a+x b-w \sqrt{x^{2}+1}\right)^{2}\right)}
$$

where $x$ is a real root, in the interval $\left(0, \sqrt[3]{\frac{a}{b}}\right)$, of:

$$
\left(b x^{3}-a\right)^{2}-w^{2}\left(x^{2}-1\right)^{2}\left(x^{2}+1\right)=0
$$

This automated MAT functionality was tested for various configurations of $90^{\circ}$ turns, including hospital dimensions that accord with UK guidance [5]. 24 component test cases confirmed that the algorithm performs as expected by identifying the routes in which objects can operate. Given the positive results to these tests, this approach is then adopted within the overall model.

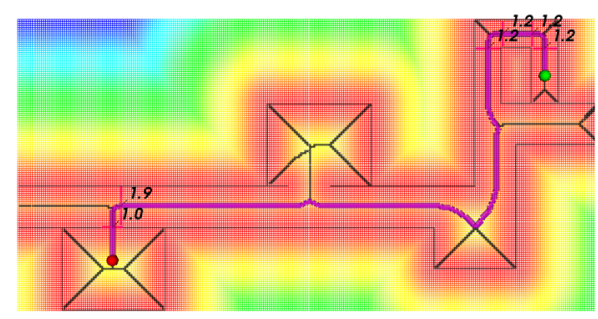

Route:

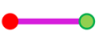

(a) Room 1 to the Stairwell

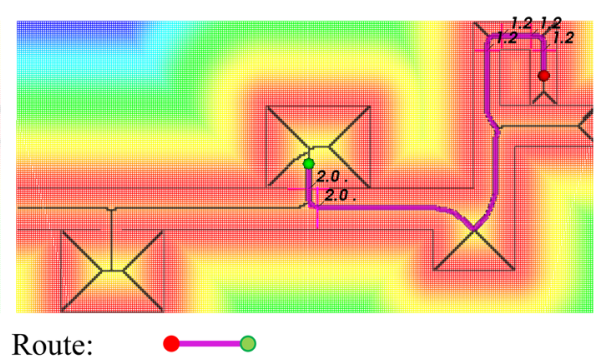

(b) The Stairwell to Room 2

Figure 2. Central paths along the medial axis to describe routes (a) and (b). Red indicates relatively close proximity to a boundary; blue indicates relative distance. 


\subsection{Agent-Object Interactions}

In the OM, cartesian coordinates are used to represent the birds-eye shape and area of objects. It is therefore technically permissible to define non-rectangular quadrilaterals and other polygons. However, irregular shapes may not be appropriate for the pre-simulation route assessment described in the previous section as this model is based on strictly rectangular geometric calculations. Therefore, assumptions are required in order to represent complex shapes, and it is the user's responsibility to consider the modelling implications of their methodology. For example, if a patient is to be moved from intensive care, equipment such as portable ventilators, suction equipment, and defibrillators may be attached to the front, back or sides of the wheeled bed. In this case, the bed shape will be highly irregular. It would therefore be appropriate to approximate the evacuating shape by the smallest best-fit rectangle, encompassing the bed and equipment as a whole, instead of representing the complex plan-view, under the assumption that the space required is slightly larger than the object itself.

Coordinates are used to associate agents to objects by designating target attachment points for handlers as presented in Table 6 .

For simulation, the footprint of the agents attached to objects is represented as depicted in Table 6, once all handlers are present at the attachment points. Agents' speeds and behaviours, e.g. conflict resolution between agents competing for space, group dynamics, wayfinding, were developed in bEX over years of research [44]. In the OM, these algorithms are still in use, so apply to agents when they are not operating a device. However, agents who are operating a device are allocated a pre-determined itinerary of tasks. The attachment points provide the target locations for these itineraries.

In the OM, only one object or agent can be positioned on a node at any given time. The number of nodes an object occupies depends on it position. This is demonstrated in Fig. 3, where a device is placed within a nodal grid and a radial function detects whether the device is on each node.

This provides a means for agents and devices to be specified alongside each other and interact in accordance with the nodal spaces available, i.e. as other agents will occupy the surrounding nodes available as required. For a $0.5 \mathrm{~m} \times$ $0.5 \mathrm{~m}$ nodal grid, a $0.2 \mathrm{~m}$ radial function was sufficient for the $\mathrm{OM}$ as indicated by iterative testing, but this can be modified within the model to represent agentdevice dynamics for other objects.

Simulated handlers follow the set of tasks specified in Fig. 1, to pick up and drop off the devices, adopting appropriate speeds and delays times according to the Ghent data. This utilizes existing bEX itinerary functionality along with newly developed agent capabilities to allow this handler role to be specified and adopted. The gender of the handling team informs the preparation times and movement speeds adopted; if any member of the team is female, they will adopt an all-female preparation time and speed. Once moving with a device, the handlers are rigidly attached to the device in their handling locations. 


\section{Table 6}

Coordinates for Dimensions and Attachment Positions for Device Objects in Horizontal and Vertical Handling Positions

\begin{tabular}{|c|c|c|c|}
\hline \multicolumn{2}{|c|}{ Stretcher: Horizontal/ Vertical } & \multicolumn{2}{|c|}{ Evacuation Chair: Horizontal/ Vertical } \\
\hline$\stackrel{A}{{ }_{1}}$ & $\begin{array}{ll}\text { DIMENSIONS } & \text { ATTACHMENT } \\
P_{o}(0.00,0.00) & A(0.00,1.66) \\
P_{1}(0.00,1.66) & B(0.43,1.66) \\
P_{2}(0.43,1.66) & C(0.00,0.00) \\
P_{3}(0.43,0.00) & D(0.43,0.00)\end{array}$ & $\bar{A}$ & $\begin{array}{l}\text { DIMENSIONS ATTACHMENT } \\
P_{o}(0.00,0.00) A(0.26,0.00) \\
P_{1}(0.00,0.77) \\
P_{2}(0.52,0.77 \\
P_{3}(0.52,0.00)\end{array}$ \\
\hline \multicolumn{2}{|c|}{ Carry Chair (M/F): Horizontal } & \multicolumn{2}{|c|}{ Carry Chair (M): Vertical } \\
\hline $\mathrm{A}$ & $\begin{array}{ll}\text { DIMENSIONS } & \text { ATTACHMENT } \\
P_{o}(0.00,0.00) & A(0.24,0.00) \\
P_{1}(0.00,0.61) & \\
P_{2}(0.48,0.61) \\
P_{3}(0.48,0.00)\end{array}$ & $\stackrel{A}{B}$ & $\begin{array}{l}\text { DIMENSIONS } \quad \text { ATTACHMENT } \\
P_{o}(0.00,0.00) A(B) * \\
P_{1}(0.00,0.61) B(0.24,0.61) \\
P_{2}(0.48,0.61) C(0.24,0.00) \\
P_{3}(0.48,0.00)\end{array}$ \\
\hline \multicolumn{2}{|c|}{ Carry Chair (F): Vertical } & \multicolumn{2}{|c|}{ Rescue Sheet: Horizontal } \\
\hline$\frac{A}{C}$ & $\begin{array}{ll}\text { DIMENSIONS } & \text { ATTACHMENT } \\
P_{o}(0.00,0.00) & A(0.00,0.61) \\
P_{1}(0.00,0.61) & B(0.48,0.61) \\
P_{2}(0.48,0.61) & C(0.00,0.00) \\
P_{3}(0.48,0.00) & D(0.48,0.00)\end{array}$ & A B & $\begin{array}{ll}\text { DIMENSIONS } & \text { ATTACHMENT } \\
P_{o}(0.00,0.00) & A(0.00,2.00) \\
P_{1}(0.00,2.00) & B(0.75,2.00) \\
P_{2}(0.75,2.00) & \\
P_{3}(0.75,0.00) & \end{array}$ \\
\hline \multicolumn{2}{|c|}{ Rescue Sheet: Vertical } & \multirow{2}{*}{\multicolumn{2}{|c|}{$\begin{array}{l}\text { * THE THIRD HANDLER FOR THE CARRY CHAIR } \\
\text { SWAPS INTO POSITION B AT REST PERIODS, } \\
\text { SO A THIRD ATTACHMENT POINT IS NOT } \\
\text { REQUIRED. }\end{array}$}} \\
\hline A & $\begin{array}{ll}\text { DIMENSIONS } & \text { ATTACHMENT } \\
P_{o}(0.00,0.00) & A(0.28,0.00) \\
P_{1}(0.00,2.00) & B(0.28,2.00) \\
P_{2}(0.75,2.00) & \\
P_{3}(0.75,0.00)\end{array}$ & & \\
\hline
\end{tabular}

\subsection{Horizontal Travel}

Simulated objects use a version of the bEX potential map which assigns a potential value to each node $\left(P_{x}\right)$, based on its shortest distance to a target. The node with the Lowest Node Potential $(\mathrm{LNP})=\min \left\{P_{0}, P_{1}, P_{2}, P_{3}, P_{4}, P_{5}, P_{6}, P_{7}\right\}$ represents the direction of preferred movement; i.e. the closest step to the agent's next target. 


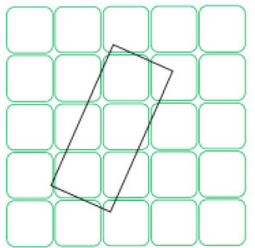

(i) A device imposed on a nodal grid

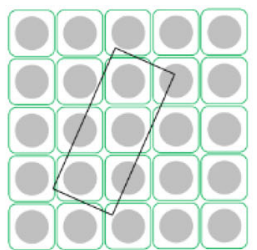

(ii) The radial function from the centre of each node;

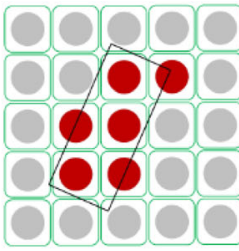

(iii) The nodes in which the device boundary intersects with the radial function.

\section{Figure 3. A demonstration of nodal occupation criteria, based on dimensions and rotational position of device.}

The location of an object is defined by its occupation of a single node. In the $\mathrm{OM}$, this point is the centre of its foremost edge (i.e. the leading face of the object in its direction of travel). Objects avoid boundaries and the edges of doorways where possible by de-prioritising them in their potential calculation. Object speeds are represented by the time spent on each successive node, recalibrated in bEX every 6th of a second. The underlying speed is determined by the appropriate Ghent data, unless the device interacts with evacuees, where the existing bX movement algorithms are employed to resolve spatial conflicts, local navigation, etc.

In the OM, objects can be orientated at one of 16 regular angles: eight of which correspond to the surrounding nodal options $\left(P_{x}\right)$. Bisecting these, a further eight angles is considered to increase the scope of object movement: $M_{i, j}$, where $i$ and $j$ are the two nodes bisected. $P$ values are the potential values of the surrounding nodes, $M$ values are the mean value of the two adjacent $P$ values. $a P$ and $a M$ values are then all of the associated angles, as specified in Fig. 4. In this way, the algorithm considers a second degree of nodal locations in the determination of the device movement in order to make its path more naturalistic.

The calculation taken to determine a devices' angle at a given point is based on the $\mathrm{P}$ values surrounding the next point on its path; therefore, any upcoming turns are anticipated in advance. Figure 5 depicts this angle selection, with the eight $P$ values as input and angles of orientation $\left(P_{\text {choice }}\right.$ or $\left.M_{\text {choice }}\right)$ as output.

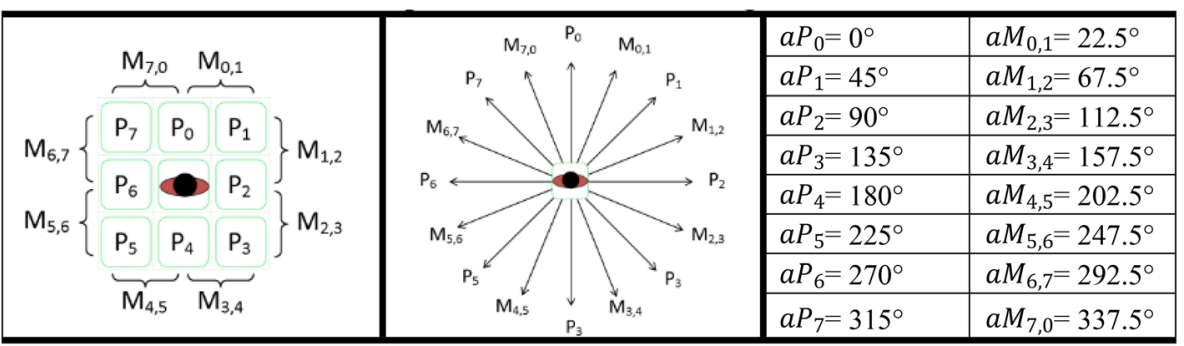

Figure 4. Object orientation parameters and corresponding potential field, relating node options with rotational angle. 


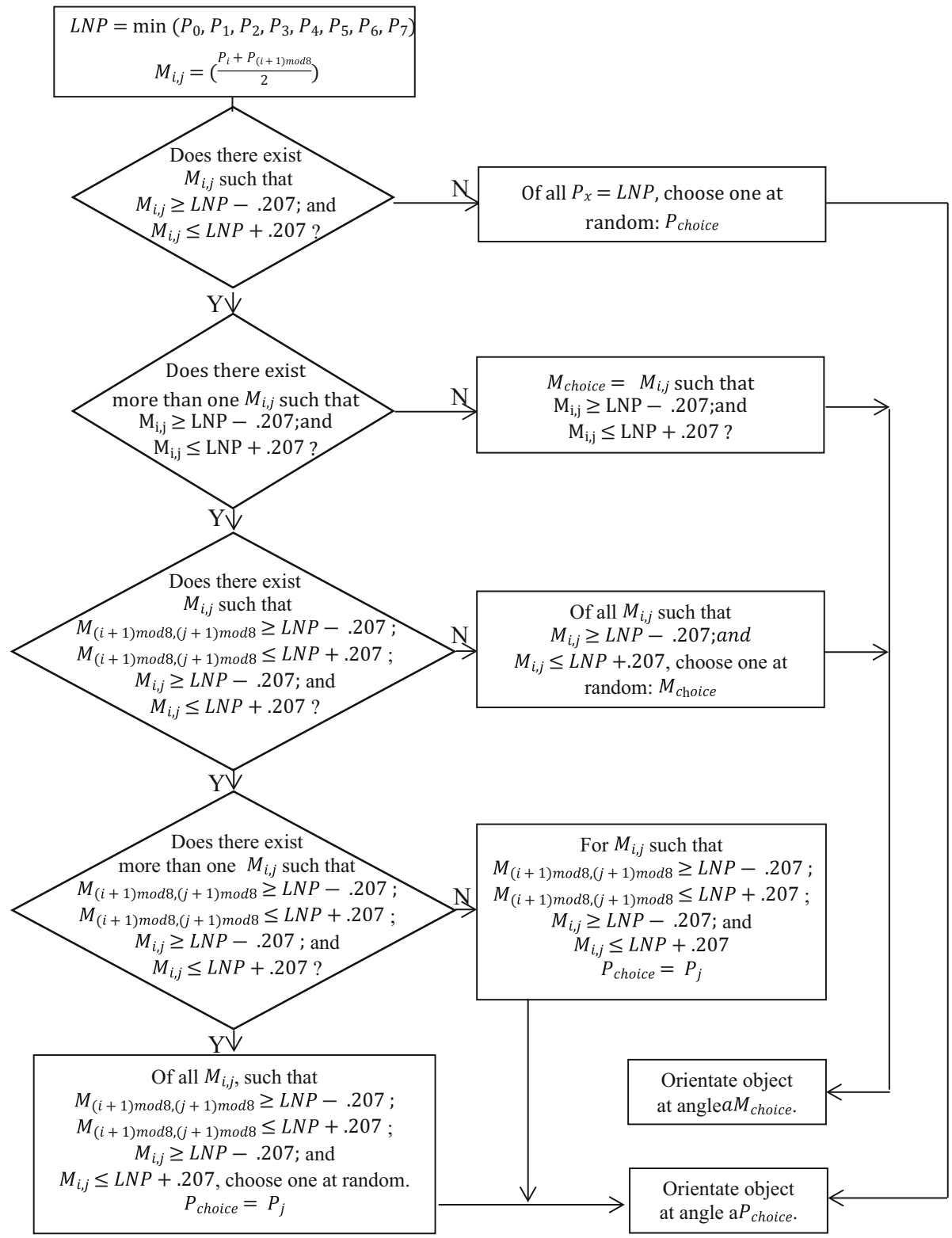

\section{Figure 5. Horizontal object orientation flowchart, defining the process by which rotational position of object is established.}

As depicted in Fig. 5, $M$ values are initially calculated as the mean of successive $\mathrm{P}$ values, and a comparison is made to detect whether any are within 0.207 of the $L N P$, indicating a directional bias towards the $M$ value's associated angle. The value 0.207 is used for the range in this comparison of potential values as it is the 
typical difference between horizontal and diagonal arc lengths based on a $0.5 \mathrm{~m} \times$ $0.5 \mathrm{~m}$ nodal grid, i.e. $0.707-0.5$. If there are no $M$ values that satisfy this condition, the $L N P$ or random equivalent node is selected. Where there is only one $M$ value that satisfies this condition, this variable is selected. Where there is more than one $M$ value that satisfies the condition, the algorithm checks whether these form any adjacent pairs; i.e. in the case that they share a $M$ value in their initial mean calculation; $i=j$. If there are no pairs, one $M$ value is randomly selected as the output variable, with a preference for maintaining the current angle. If there is more than one pair, then one is selected at random, with a preference for maintaining the current angle. In this case, where consecutive $M$ values fall within range of the $L N P$, their common $P$ value is the output variable. The resulting angle will correspond to the directional aim of the object, while aligning with its navigation and spatial objectives, to ensure a smooth path through the nodal grid.

\subsection{Door Transition}

In hospitals, double swing doors are most appropriate for movement of devices such as beds and doors, ideally opening outwards in the direction of the evacuation route, as they are more likely to provide sufficient width and ease of use than a single leaf door. This directionality is not always possible as progressive horizontal evacuation will often require movement in both directions. Therefore, two different door types are introduced in the OM: Door Type 1 in which the double leaves open towards the object, and Door Type 2 in which the double leaves open away from the object.

In bEX, doors have size attributes, signage indicators, and can be open or closed. In the OM, when an object is positioned in a doorway a new speed is adopted based on the available data. Door transition times are: $\boldsymbol{d}_{\boldsymbol{d} 1}$ seconds for the Door Type 1, and $\boldsymbol{d}_{\boldsymbol{d} 2}$ seconds for the Door Type 2. The speed associated with this delay is dependent on the length of the device $\left(\boldsymbol{m}_{\boldsymbol{l}}\right)$, as the distance travelled at the reduced speed will be greater for longer devices. Therefore, the following directive is employed: if an object's next step will result in any part of the object being positioned on a door node of door type $i$, it will adopt speed: $D_{\text {Speed }}=\frac{\boldsymbol{m}_{l}}{\boldsymbol{d}_{d i}}$ $(\mathrm{m} / \mathrm{s})$ for $\boldsymbol{d}_{\boldsymbol{d i}}$ seconds.

\subsection{Vertical Travel}

In vertical travel, it was found that the number/location of places at which objects stopped on the stairwell was typically a primary determinant in the speed attained per floor, and allowed overtaking by other evacuees [22]; therefore the process of stopping is modelled explicitly (rather than using a lower average travel speed). To simulate the devices periodically stopping within the OM, speed variables are interpolated to represent each travel speed excluding stoppages, enabling the stops to be represented (i.e. explicitly simulated) as intermittent delays. Interpolated vertical speeds $\left(s_{v}\right)$, are presented in Table 7 , where the speeds associated with the floors in which stoppages occurred are removed, and the data are interpolated as an average from the surrounding data points. 


\section{Table 7}

Interpolated Vertical Speeds (m/s) with Stopping Influence Removed for Male, Female and All Handling Teams

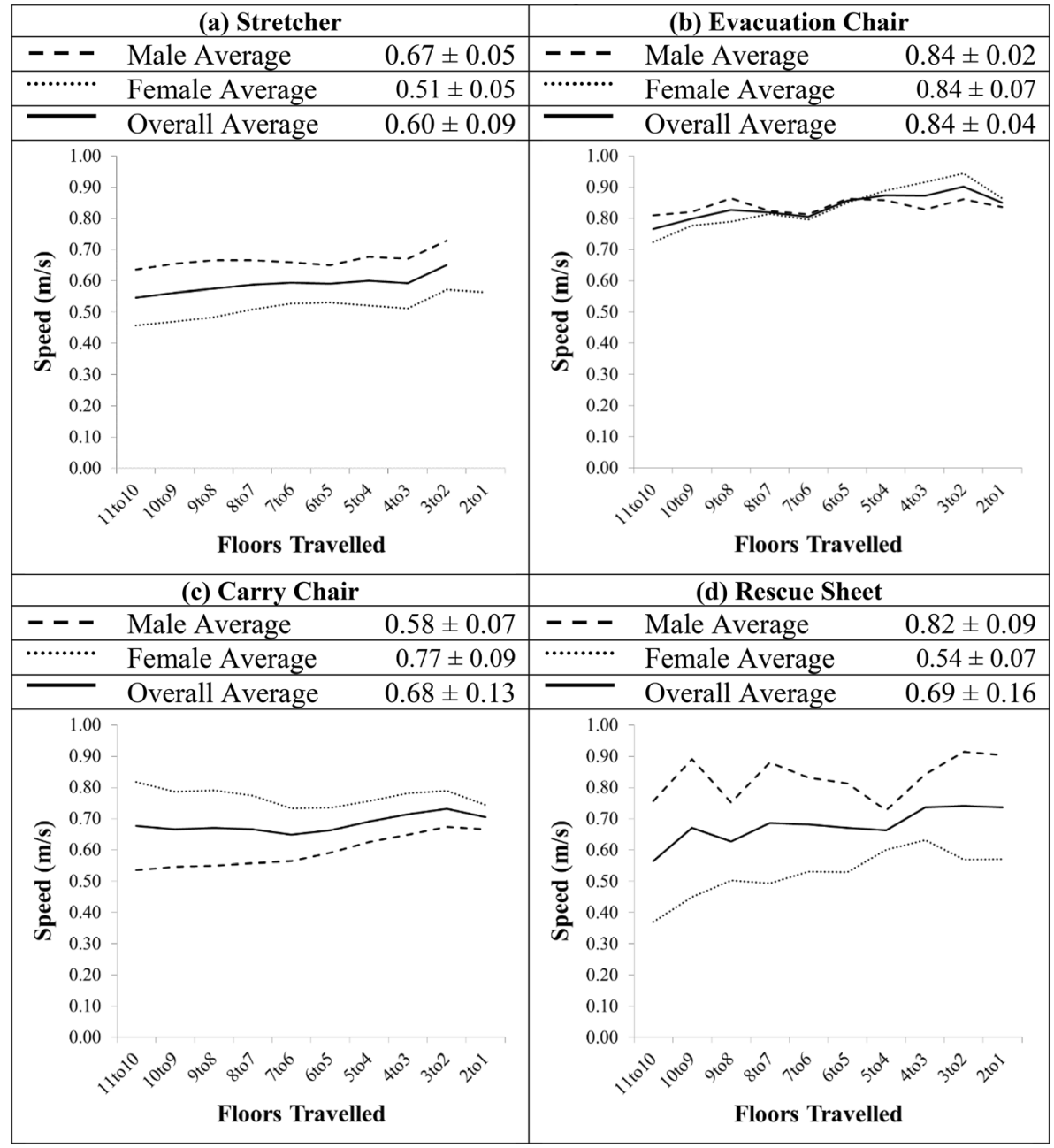




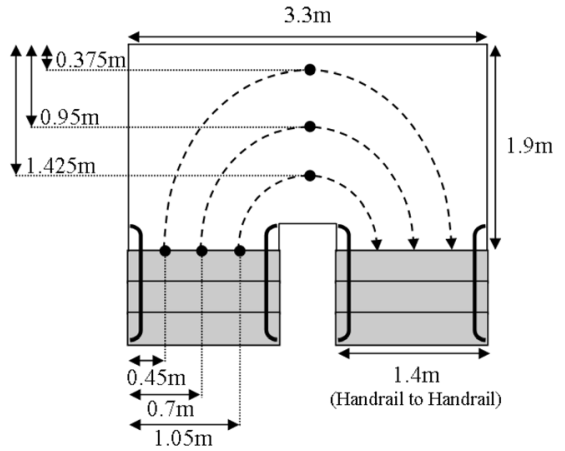

(i)

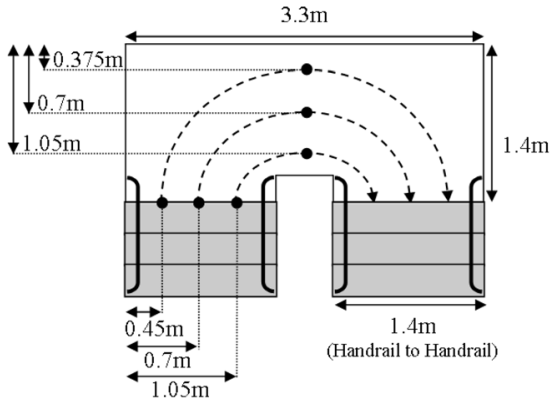

(ii)

Main landing device position measurements Sub landing device position measurements

\section{Figure 6. Entry and landing positions in two-lane staircases for (i) main landing of effective depth $1.9 \mathrm{~m}$ and (ii) sub-landing of effective depth $1.4 \mathrm{~m}$.}

Objects typically form lanes in stairs reflecting the nature of the path adopted and the occupancy of a unit of the stair width in relation to the dimensions of the device itself. Depicted in Fig. 6 are the approximate measurements of the lane entry points onto each main and sub landing. This split is based on the Ghent observations, the midpoints and quartiles of the stair width, as well as the device dimensions.

Objects are categorised according to their lane occupancy, with the path travelled on each landing approximated by a segment of an elliptic shape. For a clockwise dog-leg staircase, parametric equations model this curve as bounded by the variables: entrance position $(E)$, landing position $\left(L_{P}\right)$, landing width $\left(L_{W}\right)$, and landing depth $\left(L_{D}\right)$. To represent this in a discrete event simulation engine, their paths are discretised into several steps. The data indicate that, on average, the longest time a device will spend on a landing is $10.3 \mathrm{~s}$ [22]. Therefore, to align the object's movement with bEX time-steps of $1 / 6$ th of a second, a maximum of 62 discrete steps is used when any device is moving $(10.3 / 6)$; i.e. $n=0,1, \ldots 61$.

The position of the device at step $n$ is $\left(x_{n}, y_{n}\right)$, where:

$$
\begin{aligned}
& x_{n}=\left(\frac{L_{W}}{2}-E\right)\left(\cos \left(\pi-\tau_{n}\right)+1\right) \\
& y_{n}=\left(L_{D}-L_{P}\right) \sin \left(\pi-\tau_{n}\right) \\
& \tau_{n}=\frac{\pi n}{61}
\end{aligned}
$$

The object's angle in degrees at position $\left(x_{n}, y_{n}\right)$ is: 


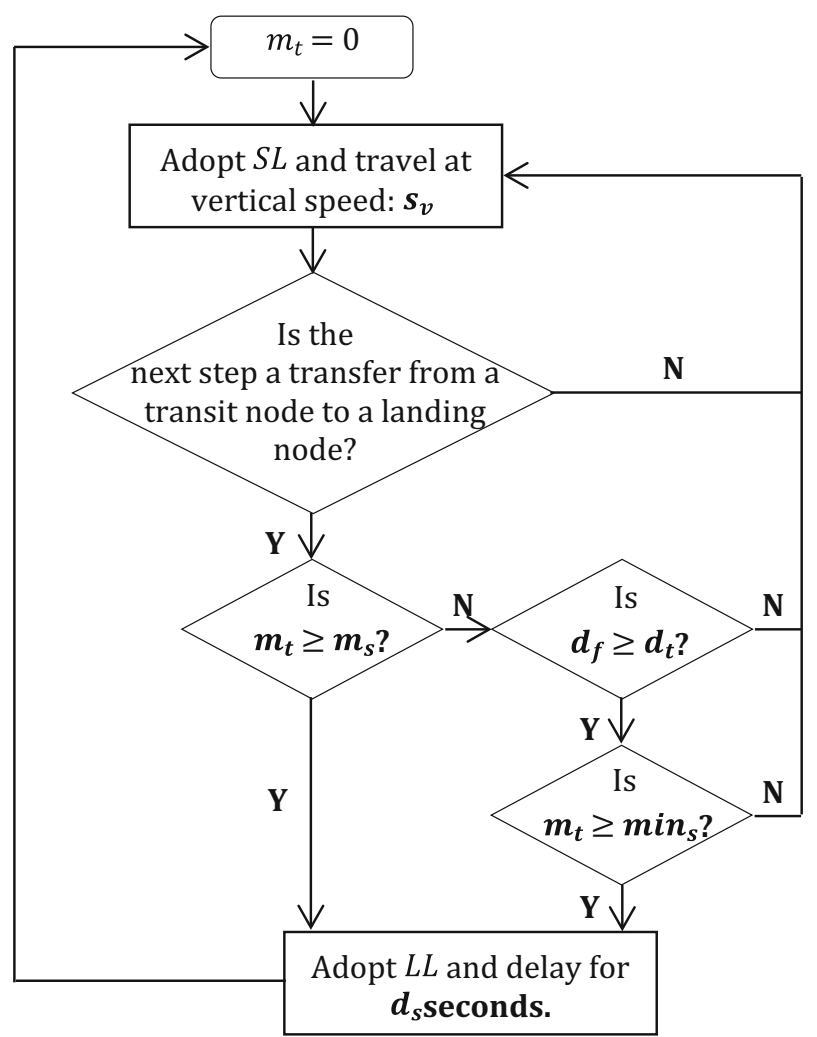

\section{Figure 7. Object vertical stoppage model flow chart identifying the} need and extent of movement delay.

$$
\theta^{\circ}=90-\frac{180}{\pi} \tan ^{-1}\left(\frac{-\left(L_{D}-L_{P}\right)^{2}\left(x_{n}-\frac{L_{W}}{2}+E\right)}{\left(\frac{L_{W}}{2}-E\right)^{2} y_{n}}\right)
$$

The time at which the object enters the landing is recorded as $T_{n}$ (when $n=0$ ). Then the time at each subsequent step $T_{n}$ (when $n>0$ ) is simply the distance travelled divided by the interpolated vertical speed $\left(s_{v}\right)$ :

$$
T_{n}=T_{n-1}+\frac{\sqrt{\left(x_{n}-x_{n-1}\right)^{2}+\left(y_{n}-y_{n-1}\right)^{2}}}{s_{v}}
$$

As each successive time-step elapses in bEX, the object moves to the step with the highest $T_{n}$ value below the time on the simulation clock, and is orientated according to the equations above. 


\subsection{Vertical Stopping Algorithm}

An overview of the vertical stopping algorithm is presented in the flowchart in Fig. 7, in terms of the stair lane occupied (SL) and the landing land occupied (LL), where $d_{s}$ is the stopping duration (in seconds) and $m_{s}$ is the stopping frequency (in metres travelled).

This process ensures that stops will be at a maximum of $\mathrm{m}_{\mathrm{s}}$ metres apart, but may also occur more frequently, based on the population density preceding the device; i.e. the other evacuees using a stairway may interfere with the passage of the device forcing it to stop.

\section{Model Testing}

There are currently no definitive standards for the testing of building evacuation simulations. We now adopt the most comprehensive tests available (i.e. ISO/TR 16730-5:2013 [52] and NIST [53]) and a battery of new tests to quantify the movement of beds and movement devices, in both horizontal and vertical evacuations.

The full testing process employed to examine the implementation and impact of the developments described in this article is available in the author's thesis [22], including: Component Testing, where individual components of the implemented model are tested to ensure they function as intended; and Functional Verification, where the model's ability to perform simulations of hospital evacuation is analysed; i.e. to verify the collective performance of the different model components. This test compares the predictive capability of the new functionality with results produced by manually configuring the simulation tool (that act as a proxy for real-world expectation). For each test, qualitative and/or quantitative verification was conducted to compare the simulation model against experimental data presented in this paper, as briefly outlined here.

It should be noted that genuine validation data are not available. There is no extant data-set that sufficiently documents a full-scale case, including the individual devices used, the scenario, the procedure and the overall evacuation performance for an instructive validation test to be performed. The approach adopted here is designed to test the new modelling functionality, to ensure that the theoretical model functions as designed, and replicates the benchmark data from the Ghent trials individually and in a hypothetical test case employing user-driven model results derived from the experimental observations as a proxy for a realworld benchmark. This last test is particularly important as it shows that the model might operate equivalently to an expert user manually approximating the experimental data.

\subsection{Route Assessment-Component Testing}

The route assessment functionality was tested for several $90^{\circ}$ turns using realistic hospital dimensions that accord with UK codes [5]. The following tests were undertaken, representing the typical geometrical configurations to be analysed in a hospital: 
- Tests 1-2 Identifying one corner

- Tests 3-5 Identifying two corners in a dog-leg configuration

- Tests 6-9 Identifying two corners in a snake configuration

- Test 10 Not identifying any corner in an intersecting snake configuration

- Tests 11 (i), (ii), and (iii) Identifying three corners

- Tests 12 (i), (ii), and (iii) Identifying two corners in a three-corner configuration with one intersecting corner

Of the 32 test cases investigated, 28 detected all of the right-angled corners with errors as expected between $0.00 \mathrm{~m}$ and $0.20 \mathrm{~m}$. The four cases in which corners were not identified indicate that on paths where there were wider passageways connecting to smaller passageways (i.e. by a factor greater than two), then the wider turn was not recognised as a right angle. However, as the smaller turn was identified, it was found that the path was still satisfactorily analysed.

\subsection{Object Specification-Component Testing: The objects generated were as intended}

The following tests were conducted on the model to verify the physical representation and agent interactions, for all devices and for male and female handling teams:

- Test 13 Representation of device size - comparison between dimensions of object and expectation

- Test 14 Representation of device area-comparison between footprint of object and expectation

- Test 15 Agent preparation and collection of device-comparison between performance delays and expectation

It was found that the model precisely represents the correct device dimensions with respect to the surrounding boundaries. The devices also occupied the correct area, as specified by their shape and successfully displaced the correct number of agents (i.e. other agents do not overlap with the device). Agent-device interactions were tested and it was found that the specified preparation delay was incurred for all devices and teams of all genders. The attachment algorithm worked as prescribed as associated agents picked up, moved with, and dropped off the devices using the correct horizontal and vertical positioning.

\subsection{Horizontal Travel-Component Testing: The generated object travelled horizontally as expected}

The following tests were conducted to test the horizontal movement algorithms, for all devices and for male and female handling teams:

- Test 16 Speed of device in a corridor-comparison between achieved travel speed and expectation 
- Test 17 Representation of path blockage by a device-ensure device could not pass through perceived route blockage

- Test 18 Device navigation around corners - ensure no parts of device passed through boundary

- Test 19 Device navigation through doors - ensure no parts of device passed through exit boundary

The speed of each device was tested on the horizontal and it was found that all devices travelled at the prescribed speed within the model, with only minor errors noted: $\varepsilon \leq 0.8 \mathrm{~s}$, likely due to minor differences in the path adopted. It was also found that paths were appropriately blocked by devices, where agents could not pass, and that agents only moved around the devices where there was room in the geometry i.e. vacant nodes adjacent to the device. Devices successfully navigated the corridor geometry, including corners and doorways. The test cases demonstrated that the correct time elapses when each of the devices are pushed and carried through doorways within the model with minor errors noted: $\varepsilon \leq 0.4 \mathrm{~s}$.

\subsection{Vertical Travel-Component Testing: The generated object travelled vertically as expected}

The following tests were conducted using a stairwell geometry based on the emergency stairwell layout in the Ghent trials, for all devices and for male and female handling teams:

- Test 20 Speed of device descending stairs - comparison between achieved travel speed and expectation

- Test 21 Stopping frequency in stairwells - comparison between predicted number of staff stops predicted by stopping algorithm and expectation

- Test 22 Ability to overtake device in stairwells - identification of other evacuees passing device where opportunity arises.

It was found that all devices travelled at the prescribed speed per floor within the model, with only minor errors noted: $\varepsilon \leq 0.8 \mathrm{~s}$, likely due to minor differences in the path adopted. Furthermore, the stopping algorithm indicated that the correct number and duration of stops incurred in the model. The ability for other agents to overtake each device was tested, and it was found that the devices that left a stair lane open (i.e. the evacuation chair and the carry chair with male teams) successfully permitted other agents to pass on the stairs. For those devices that fully occupied the stairs, agents could only pass when the device had stopped on the landing.

All cases show qualitatively and quantitatively acceptable outputs, and verify the random element to horizontal movement (i.e. stochastic decisions are made where two or more optimal routes are presented). The tests indicated that the model is effective in reproducing the hospital evacuation behaviour observed in the Ghent trials. 


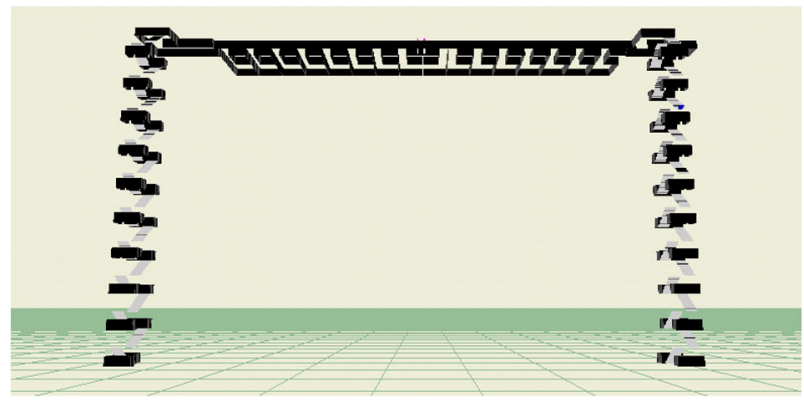

\section{Figure 8. Functional verification geometry in bEX, involving} horizontal plane and stair configuration.

\subsection{Repeated Patient Collection-Functional Verification: Model predictions equivalent to user-driven model predictions (i.e. when model configured by expert)}

A user-driven simulation was conducted by Hunt et al. [43], based on the Ghent hospital layout that implicitly represented devices as groups of evacuating agents; i.e. an expert user configured the model manually to represent the assembling and disbanding to represent repeated collection, and travelling at device speeds using the model functionality available at the time. In this section, the same scenarios are predicted using the explicit object model in bEX. The results are then compared to simulations produced by the user driving the model; i.e. the newly expanded model functionality is used to represent the same procedure without user intervention. This test was designed to verify the collective performance of the different model components to determine that they function as expected when interacting; i.e. that they function in concert with each other, and that they then

\section{Table 8}

Functional Demonstration Results Derived from Numerical Calculations and Simulation Output

\begin{tabular}{|c|c|c|c|c|c|c|c|c|}
\hline \multirow[b]{3}{*}{ Device } & \multicolumn{4}{|c|}{ Numerical simulation results } & \multicolumn{4}{|c|}{ BEX simulation results } \\
\hline & \multicolumn{2}{|c|}{ Male teams } & \multicolumn{2}{|c|}{ Female teams } & \multicolumn{2}{|c|}{ Male teams } & \multicolumn{2}{|c|}{ Female teams } \\
\hline & $\begin{array}{l}\text { Day } \\
\text { (h) }\end{array}$ & $\begin{array}{l}\text { Night } \\
\text { (h) }\end{array}$ & $\begin{array}{l}\text { Day } \\
\text { (h) }\end{array}$ & $\begin{array}{l}\text { Night } \\
\text { (h) }\end{array}$ & $\begin{array}{l}\text { Day } \\
\text { (h) }\end{array}$ & $\begin{array}{l}\text { Night } \\
\text { (h) }\end{array}$ & $\begin{array}{l}\text { Day } \\
\text { (h) }\end{array}$ & $\begin{array}{l}\text { Night } \\
\text { (h) }\end{array}$ \\
\hline Stretcher & 3.3 & 3.8 & 3.9 & 4.7 & 3.3 & 3.8 & 4.0 & 4.5 \\
\hline $\begin{array}{l}\text { Evacuation } \\
\text { chair }\end{array}$ & 0.5 & 0.9 & 0.6 & 1.1 & 0.5 & 0.9 & 0.6 & 1.0 \\
\hline Carry chair & 1.6 & 3.1 & 3.2 & 3.5 & 1.7 & 3.3 & 3.2 & 3.5 \\
\hline Rescue sheet & 1.1 & 1.6 & 1.5 & 2.1 & 1.2 & 1.5 & 1.6 & 2.0 \\
\hline
\end{tabular}


produce credible output when compared to the manually configured simulation performed earlier.

As depicted in Fig. 8, the model is of a ward situated on the 11th floor of a hospital building, based on the Ghent University Hospital Dermatology/Pain Clinic ward. There are two emergency staircases, each constructed in a dog-leg configuration. The effective width of the staircase is $1.5 \mathrm{~m}$; there are 12 risers on each stair; and each landing has dimensions $3.4 \mathrm{~m}$ by $2.4 \mathrm{~m}$.

It was assumed that the ward is fully occupied with 28 patients and that all patients had reduced mobility, requiring full assistance to evacuate, and that only members of ward staff were available to assist in the evacuation. In accordance with Ghent Hospital rotas, the simulations were configured to represent their normal day shift (seven) and night shift (four) staff members The four movement devices would normally be used in turn to evacuate the entire ward. 16 scenarios were simulated including: each of the four devices; all-male and all-female teams; and day and night staff availability. The staff were tasked with collecting a patient and then transporting them via the device to a place of safety at the bottom of the stairs before returning for another patient. The impact of these factors upon the overall performance can then be examined.

As presented in Table 8 , the results indicate that the evacuation duration for the explicit simulation in bEX replicate the times recorded during the expert-driven numerical simulation (that encapsulated expected performance levels from the experimental observations). This demonstrates that the implemented functionality performs as expected, and that the model is at least as effective as the user-driven solution that might act as a proxy for a real-world comparison in this case. It achieves this by explicitly representing the device, staff interaction with the device and the resultant performance based on the number and nature of the staff available and the device employed.

This test satisfies the conditions set with each case demonstrating that a credible evacuation time is predicted when explicitly simulating the repeated collection of patients in bEX (with error: $\varepsilon \leq 6 \%$ ). While small variations are expected due to the stochastic nature of the simulation, the explicit modelling sufficiently predicts the numerical calculation. These tests are therefore indicative of the model's ability to simulate the horizontal and vertical hospital evacuation outlined in this scenario.

The tests demonstrate that the new model functionality represents the observed experimental performance when applied to an expanded scenario. The expert-configured model effectively has the experimental behaviours hard-wired into the model to reflect the device/handler performance; the newly modified model predicts these outcomes without the user intervention.

\section{Discussion and Future Research Pathways}

This work represents an attempt to simulate the movement of PRM during an evacuation given the use of movement devices. It does this by representing the presence and movement of the device itself (given the building geometry), the pro- 
cedural requirements of the devices (i.e. the number and identity of staff), the vertical and horizontal movement rates achievable by the device when being moved, and the interruptions of this movement due to staff stopping through fatigue. The combination of these elements was previously not satisfactorily represented in evacuation simulation tools, which had previously only represented the reduction in travel speed and/or the physical presence of a device independent of geometrical or procedural elements. The capacity to simulate this process in a more representative manner is more likely to capture the movement of PRM (and associated staff) during an emergency evacuation procedure and also the impact of this movement on other evacuees. This should help ensure that the simulation process (although still a simplification) excludes fewer factors that inhibit evacuation performance and is less likely to produce unduly optimistic predictions.

It is acknowledged that, although this effort represents an important step in the simulation of PRM movement, more work is required. The process of development has also highlighted other model developments that may be considered to further enhance the functionality: the representation of patient preparation from varying initial positions (e.g. lying down) and the attachment of medical equipment; the adjustment of speeds in light of new performance factors such as levels of training, device weight, handler fatigue, and the different physical capabilities within a handling team; and the behaviours of evacuees travelling alongside and overtaking devices in a dense flow. Better information about device acceleration, momentum and braking would also support an improved model of device movement.

A worthwhile development would be adaptable agent itineraries to enable the simulation of agents who are not staff (e.g. visitors and other hospital staff) to aid in the assistance of PRM. Furthermore, itineraries that are conditional on a developing situation, or based on communication between agents would greater represent the reality of hospital procedures, particularly the communication and interaction between hospital staff and emergency responders.

As noted previously, the advances made during this work can also be extended to non-healthcare environments to address the presence of luggage, prams, mobility scooters, etc. This work is ongoing.

\section{Conclusion}

Hospitals are complex spatial environments, and evacuations require moving vulnerable occupants to a place of safety. It is critical to understand the performance of vertical evacuation strategies, particularly the means by which people with reduced mobility can be assisted in stair descent. This paper outlined the algorithms implemented to explicitly represent the dynamics of evacuation devices within evacuation software.

The model developed in this work specified movement devices in terms of the parameters identified in the experimental data. Devices are specified using rectangular vertices, sufficient for approximating wheelchairs, beds, stair movement devices, and other medical equipment. Experimental data were also associated with 
the object to indicate the speed at which it travels, associated preparation times, as well as the size and space it occupies and the number of handlers required. Algorithms were presented that enable devices to move within a fine-node system, to navigate alongside other agents on a flat surface and on stairs, and to manoeuvre corners and doorways during the simulation in accordance with the data collected. The gender of the handlers informed the speeds applied. A stopping model is also presented, to represent the devices stopping periodically within the stairwell, as indicated by the experimental results. Numerous quantitative and qualitative testing was conducted. This demonstrated that the model developed as part of this work is effective in reproducing the hospital evacuation behaviour observed in the data collected during this work (e.g. during the Ghent trials) and that it is suitable for application within broader hospital scenarios.

Prior to the data collected during the Ghent trials, there were insufficient data to understand and quantify the performance of evacuation devices. Although further work is still required, the data collected has significantly enhanced understanding and capacity to quantify the performance of a number of different devices. Importantly, it also enabled the explicit simulation of this performance within an evacuation model. This is a significant and novel development, given the functionality that had to be introduced to cope with the procedural, navigational and geometric aspects of the use of the device. This has now been achieved and demonstrated to adequately represent the real-world behaviour being simulated.

This enhancement now allows practitioners and interested parties to test the use of evacuation devices as part of different hospital evacuation procedures and their impact (positive or negative) on overall performance - and to quantify the factors that influence this performance. This significantly enhances planning and diagnostic capabilities of the model within hospital and other healthcare facilities. This forecasting capacity enables insight to be gained prior to the implementation of a new procedure, a new building design or the use of new devices. As such, it should help ensure that the adoption of new designs is better informed and that risk assessments and evidence-based analyses are better supported in the future.

\section{Acknowledgements}

This work was co-sponsored by the Fire Safety Engineering Group at the University of Greenwich and the Engineering and Physical Sciences Research Council (EPSRC) Doctoral Training Award. It was conducted in collaboration with University Hospital Ghent.

\section{Open Access}

This article is licensed under a Creative Commons Attribution 4.0 International License, which permits use, sharing, adaptation, distribution and reproduction in any medium or format, as long as you give appropriate credit to the original author(s) and the source, provide a link to the Creative Commons licence, and indicate if changes were made. The images or other third party material in this 
article are included in the article's Creative Commons licence, unless indicated otherwise in a credit line to the material. If material is not included in the article's Creative Commons licence and your intended use is not permitted by statutory regulation or exceeds the permitted use, you will need to obtain permission directly from the copyright holder. To view a copy of this licence, visit http://creat ivecommons.org/licenses/by/4.0/.

\section{References}

1. British Standards Institution (2008) BS 9999:2008 Code of Practice for Fire Safety in the design, management and use of buildings. British Standards Institution, London

2. Johnson CW (2006) Using computer simulations to support a risk-based approach for hospital evacuation. A Department of Computing Science Briefing, Glasgow Accident Analysis Group, University of Glasgow, Glasgow

3. Childers A, Taaffe K (2010) Healthcare facility evacuations: lessons learned, research activity, and the need for engineering contributions. J Healthc Eng 1:125-140

4. HMG (2005) The regulatory reform (fire safety) order. HMG, London

5. Department of Health (2015) Health technical memorandum 05-02: firecode guidance in support of functional provisions 2015 edition. https://www.gov.uk/government/public ations/guidance-in-support-of-functional-provisions-for-healthcare-premises. Accessed 29 Aug 2017

6. Wapling A, Heggie C, Murray V, Bagaria J, Philpott C (2009) Review of five London hospital fires and their management. NHS London, London

7. Lubin R (2017) Chapel Allerton Hospital 'partially evacuated' in Leeds after reports of suspicious package in toilet. MGN Ltd. http://www.mirror.co.uk/news/chapel-allerton-h ospital-partially-evacuated-10586314. Accessed 29 Aug 2017

8. Pamer M, Mecham D (2015) Culver City Hospital evacuated due to fire; 120 patients, 220 staffers moved," KTLA, 2015. http://ktla.com/2015/01/29/culver-city-hospital-evacu ated-due-to-fire-patients-moved-outside/. Accessed 29 Aug 2017

9. HMG (2006) Fire safety risk assessment: healthcare premises. HMG, London

10. Government of Canada (2015) National model construction code documents: objectivebased codes. http://www.nationalcodes.nrc.gc.ca/eng/faq/objective_based_codes.html. Accessed 29 Aug 2017

11. The Australia Building Codes Board (2013) The national constructive code - a performance-based code. http://www.abcb.gov.au/Resources/Publications/Education-Training/ A-Performance-Based-Code. Accessed 29 Aug 2017

12. Purser DA (2003) ASET and RSET: addressing some issues in relation to occupant behaviour and tenability. Fire Safety Science 7:91-102

13. Drysdale D (2011) An introduction to fire dynamics. Wiley, Chichester

14. Kuligowski ED, Peacock RD (2010) Review of building evacuation models, 2nd edition (Report No. NIST TN 1680). National Institute of Standards and Technology, Gaithersburg

15. STEPS-Simulation Group (2011) Steps (simulation of transient evacuation and pedestrian movements) user manual. Mott MacDonald, Croydon

16. Morrow E (2010) MassMotion: simulating human behaviour to inform design for optimal performance. The Arup Journal, London, pp. 38-40 
17. Golmohammadi D, Shimshak D (2001) Estimation of the evacuation time in an emergency situation in hospitals. Comput Ind Eng 61(1256-1267):13

18. Johnson C (2005) Using computer simulations to support a risk-based approach for hospital evacuation. Technical Report, University of Glasgow

19. Alonso V (2014) Egress modelling in health care occupancies, The Fire Protection Research Foundation, USA, Retrieved July 2014

20. Alonso V (2017) The impact of a change on the size of the smoke compartment in the evacuation of health care facilities. Fire Technol . https://doi.org/10.1007/s10694-0170686-7

21. Manley MT (2012) Exitus: an agent-based evacuation simulation model for heterogeneous populations. All Graduate theses and Dissertations. Paper 1205

22. Hunt A (2016) Simulating hospital evacuation. Ph.D Thesis, University of Greenwich, London

23. Christensen K, Sasaki Y (2008) Agent-based emergency evacuation simulation with individuals with disabilities in the population. J Artif Soc Soc Simulat 11(3):9

24. SimWalk (2015) SimWalk V4.0 User Guide. http://www.simwalk.com/downloads/User Guide40.pdf. Accessed 29 Aug 2017

25. Wall J, Waterson N (2002) Predicting evacuation times - a comparison of the STEPS simulation approach with NFPA 130. Fire Command Stud 1(1):20-32

26. Boyce KE, Shields TJ, Silcock GW (1999) Toward the characterization of building occupancies for fire safety engineering: capabilities of disabled people moving horizontally and on an incline. Fire Technol 35(1):51-67

27. Commission for Equality and Human Rights (2016) What are reasonable adjustments? https://www.equalityhumanrights.com/en/advice-and-guidance/what-are-reasonable-adju stments. Accessed 29 Aug 2017

28. Equality Act (2010) (c.15), London

29. United Nations (2016) World population prospects: the 2015 revision. population division, Dept. of Economic and Social Affairs, United Nations, New York

30. Lutz W, Sanderson W, Scherbov S (2008) The coming acceleration of global population ageing. Nature 451:716-719

31. Gwynne S, Boyce K (2016) Engineering Data. In: Hurley M (ed) et alSFPE handbook of fire protection engineering, 5th edn. Springer, New York, pp 2439-2560

32. Kuligowski E, Hoskins B, Peacock R (2012) Evacuation of people with disabilities on stairs. In: Proceedings of 5th international symposium: human behaviour in fire. Cambridge, pp. 315-327

33. Adams AP, Galea ER (2010) An experimental evaluation of movement devices used to assist people with reduced mobility in high-rise building evacuations. In: Proceedings of pedestrian and evacuation dynamics: 5th international conference, Gaithersburg, pp. $129-138$

34. Brand A, Sörqvist M, Håkansson P, Johansson JE (2001) Evacuation safety for locomotion disabled people. In: Proceedings of 2 nd international symposium human behaviour in fire. Massachusetts Institute of Technology, Cambridge, pp. 26-28

35. Fujiyama F, Tyler N (2004) An explicit study on walking speeds of pedestrians on stairs. In: Proceedings 10th international conference on mobility and transport for elderly and disabled people. Hamamatsu, pp. 643-652

36. Jiang CS, Zheng SZ, Yuan F, Jia HJ, Zhan Z, Wang JJ (2012) Experimental assessment on the moving capabilities of mobility-impaired disabled. Saf Sci 50(4):974-985

37. Lavender SA, Hedman G, Reichelt PA, Mahta J, Conrad KM. Park S (2012) Ergonomic evaluation of manually carried and track-type stair descent devices used for the 
evacuation of high rise buildings. In: Proceedings of 5th international symposium: human behaviour in fire. Cambridge, pp. 340-345

38. Proulx P, Latour JC, McLaurin JW, Pineau J, Hoffman LE, Laroche C (1999) Housing evacuation of mixed abilities occupants in highrise buildings, Internal Report No. 706. National Research Council of Canada, Ottawa

39. Sano T, Omiya Y, Hagiwara I (2004) Evacuation from high-rise buildings by using an evacuation chair. In: 6th Asia oceania symposium on fire science and technology. international association fire safety science, Hefei

40. Shields TJ (1994) Fire and disabled people in buildings. J R Soc Health 114(6):304-308

41. Shields TJ, Boyce KE, Silcock GWH, Dunne B (1998) The impact of a wheelchair bound evacuee on the speed and flow of evacuees in a stairway during and uncontrolled unannounced evacuation. J Appl Fire Sci 7(1):29-39

42. Sørensen JG, Dederichs A (2012) Evacuation characteristics of blind and visually impaired people: walking speeds on horizontal planes and descending stairs. In: Proceedings of 5th international symposium: human behaviour in fire. Cambridge, pp. 304-314

43. Hunt A, Galea ER, Lawrence PJ (2015) An analysis and numerical simulation of the performance of trained hospital staff using movement assist devices to evacuate people with reduced mobility". Fire Mater 39(4):407-429

44. Galea ER, Lawrence PJ, Gwynne S, Filippidis L, Blackshields D, Cooney D (2015) Buildingexodus v6.2 user guide and technical manual. Fire Safety Engineering Group, University of Greenwich, London

45. Ewer J, Jia F, Grandison A, Galea E, Patel M (2013) SMARTFIRE V4. 3 user guide and technical manual. Fire Safety Engineering Group, University of Greenwich

46. Foskey M, Garber M, Lin MC, Manocha D (2001) A Voronoi-based framework for motion planning and maintainability applications. In: IEEE/RSJ international conference on intelligent robots and systems, Maui

47. Aurenhammer F, Klein R (2000) Voronoi diagram. Handbook of computational geometry Elsevier, Graz, pp 201-290

48. Choi HI, Choi SW, Moon HP (1997) Mathematical theory of medial axis transform. Pac J Math 181(1):57-88

49. Gürsoy HN, Patrikalakis NM (1991) Automated interrogation and adaptive subdivision of shape using medial axis transform. Adv Eng Softw Workstn 13(5-6):287-302

50. Ang PY, Armstrong CG (2002) Adaptive shape-sensitive meshing of the medial axis. Eng Comput 18(3):253-264

51. Boute RT (2004) Moving a rectangle around a corner: geometrically. Am Math Mon 111(5):435-437

52. ISO (2013) Fire safety engineering - assessment, verification and validation of calculation methods-part 5: example of an Egress model (ISO/TR 16730-5:2013), Geneva, Swizerland

53. Ronchi E, Kuligowski E, Reneke P, Peacock P, Nilsson D (2013) NIST technical note 1822: the process of verification and validation of building fire evacuation models. National Institute of Standards and Technology, Gaithersburg

Publisher's Note Springer Nature remains neutral with regard to jurisdictional claims in published maps and institutional affiliations. 